\title{
Self-Care Level in Diabetic Patients
}

\author{
Fatemeh mousavi ${ }^{1} \quad$ Parisa shojaei $^{1^{*}} \quad$ Termeh Tarjoman $^{1} \quad$ Ariana Daftarian $^{2}$ \\ 1.Department of community \& preventive medicine, Tehran Medical Science Branch, Islamic Azad University, \\ Tehran, Iran \\ 2.Philadelphia College of Osteopathic Medicine-Georgia Campus, Department of Biomedical Sciences
}

\begin{abstract}
Objective The present study was done with the objective of assessing the self-care practices among diagnosed type 2 diabetes mellitus patients in hospital of Islamic Azad University of Medical Sciences in Tehran, Iran.

Methods In this cross-sectional study, 314 Iranian patients older than 18 years of age with type 2 diabetes were completed Diabetes Self-Management Questionnaire. Data was analyzed by ANOVA, t-test, correlation and liner regression.

Results A significant association was found between the diabetes self-management sum scale and body mass index, Dietary control subscale and body mass index, Physical activity subscale and body mass index \& job and Healthcare use subscale and diabetes treatment $(\mathrm{p}<0.05)$.

Conclusion Due to the high BMI in respondents, Overweight and obese respondents need to be advised by health professionals on physical activities and proper diet to achieve healthy weights to avoid complications related to diabetes mellitus.
\end{abstract}

Keywords Diabetes self-management, Type 2 diabetes, Diabetes Self-Management Questionnaire

DOI: $10.7176 / \mathrm{JMPB} / 63-02$

Publication date: January $31^{\text {st }} 2020$

\section{Introduction}

Diabetes is a serious health problem that is responsible for four million deaths a year and $9 \%$ of all deaths in the world (3-1). Diabetes is a chronic disease that significantly affects the quality of life of people with diabetes and can lead to adverse health outcomes for individuals, families and communities (4). In 2017, 347 million people worldwide are at risk of diabetes, which is expected to increase by $55 \%$ by 2035 , while more than $90 \%$ of cases of type 2 diabetes (T2DM) (5). With increasing incidence of diabetes worldwide, it is expected to continue to be a major cause of morbidity and mortality(6). Diabetes mellitus type 2 is a chronic disease in Smalls et al. In 2014, with more than 25.3 million people in the United States and 366 million people worldwide(7) . During epidemiological studies and studies of recent decades, several epidemiologic studies have been conducted on the prevalence of Type 2 diabetes in Iran, according to which the population of diabetics in Iran in the year 87 was estimated to be more than 1.5 million. The results show that the prevalence of type 2 diabetes in Tehran and its surrounding areas and in Isfahan is between 7-8\%(8). Diabetes self-care (DSM) is a vital part of diabetes management. This disease requires special self-care behaviors of all life (9). Changes have shown that DSM has improved the quality of life (QOL) of patients with diabetes, leading to the prevention and reduction of longterm diabetes-related complications $(10,1)$. Individual motivation can be increased for self-care in a variety of ways, since self-care support, especially in developing countries, has a significant value in raising the quality of community health(11) . To prevent severe morbidity and mortality, the treatment of diabetes requires repeating the self-care behaviors required in several areas $(13,12)$. The aim of this study was to evaluate the self-care of diabetic patients in hospitals and educational centers of Islamic Azad University.

\section{Methods}

A cross sectional study was conducted in October 2016 with a sample size of 314 people. These samples included people with diabetes who had diabetes for more than a year and who were admitted to an outpatient clinic for reasons other than diabetes complications in hospitals affiliated to Islamic Azad University, Tehran Medical Branch (Amir al-Momenin-Bouali) Amir al-Momenin or Bu'ali. In order to measure diabetes selfmanagement, we used the Diabetes Self-Management Questionnaire (DSMQ). DSMQ is a reliable and reliable tool that can assess the effectiveness of self-care behaviors associated with glycemic control. In Mehravar et al (2016) study, forward and backward translation techniques for the translation and cultural adaptation of the questionnaire into the Persian language were carried out. The test-retest reliability of the scale was assessed using the intra-class correlation coefficient. With intra-class correlation coefficient values of $0.80,0.72,0.80$, and 0.81 for the glucose management, dietary control, physical activity, and healthcare use subscales of the questionnaire, respectively. The Cronbach's alpha coefficient value was 0.72 , demonstrating adequate internal consistency of the questionnaire(14). The self-reported questionnaire consists of 16 items divided into four subscales. The first subscale evaluates glucose management, and is scored by items $1,4,6,10$, and 12 of the questionnaire. The second subscale addresses dietary control and is scored by items $2,5,9$, and 13 . The third 
subscale evaluates physical activity and is scored by items 8,11 , and 15 of the questionnaire, while the fourth subscale evaluates healthcare use and is scored by items 3, 7, and 14 of the questionnaire. A sum scale score was derived as a global measure of self-care. The patient's agreement with each item was scored using a four-point Likert type scale, ranging from 0 (does not apply to me) to 3 (applies to me very much). Patient records were examined for information regarding demographic information (sex, age, body mass index [BMI], ethnicity, marital status, and education), current diabetes treatment (use of oral hypoglycemic agents and insulin), the duration of diabetes, and the presence of complications of diabetes(15). The quantitative and qualitative data are presented as mean values (standard deviation [SD]), frequency (percentage), and Inferential statistics (correlation test, T test, ANOVA and Regression). A liner regression model was used between diabetes self-management (healthcare, diet, physical activity, blood glucose) and the demographic information (age, sex, body mass index [BMI], marital status, Educational level, diabetes duration, diabetes treatment, Residency).

\section{Results}

The mean age of participants in this study was $60.46 \pm 13.48$ years. Most male participants were $52.1 \%$ (Table 1 ). The mean (SD) of the DSMQ scores is presented in Table 2. The highest subscales of DSMQ are for Healthcare use subscale $(6.45 \pm 2.35)$. According to correlation test, DSMQ sum scale with age had no significant correlation but had a negative correlation with body mass index $(\mathrm{P}=0.006)$. T-test showed the DSMQ sum scale was not significantly different between men and women in married and single individuals and in subjects with type 1 and type 2 diabetes. According to this test, the average DSMQ sum scale was higher among those with higher incomes than those without income $(\mathrm{P}=0.037)$. ANOVA showed the average DSMQ sum scale varied between educational levels $(\mathrm{P}=0.002)$ and this difference was significant between illiterate and graduate groups and higher. However, there was no significant difference between DSMQ sum scale and diabetes duration, as well as diabetes treatment. The regression model was meaningful about the relationship between DSMQ sum scale and subscale variables and independent variables of age, gender, body mass index, marital status, job, educational status, diabetes mellitus types, diabetes duration, diabetes treatment and residency $(p<0.05)$. This model, based on these independent variables, is capable of predicting DSMQ dependent changes, and the value of this explanation is 0.034 (Table 3 ).

Table 1. Patient characteristics,

\begin{tabular}{|l|l|}
\hline Characteristics & Total $(\mathrm{n}=314)$ \\
\hline Age & $60.46 \pm 13.48$ \\
\hline Body mass index $(\mathrm{kg} / \mathrm{m} 2)$ & $27.52 \pm 4.99$ \\
\hline Sex & \\
Female & $151(47.9)$ \\
Male & $164(52.1)$ \\
\hline Marital status & \\
Single & $45(14.3)$ \\
Married & $270(85.7)$ \\
\hline Educational level & \\
Illiterate & $64(20.3)$ \\
high school education & $125(39.7)$ \\
diploma and higher & $126(40.0)$ \\
\hline Diabetes duration & $2.08 \pm 1.03$ \\
\hline diabetes treatment & \\
Exclusively oral hypoglycemic agents & $186(59.8)$ \\
Exclusively insulin & $61(19.6)$ \\
Medication and insulin & $63(20.3)$ \\
\hline Residency & \\
Tehran & $276(87.6)$ \\
Out of Tehran & $39(12.4)$ \\
\hline
\end{tabular}

Table 2.The mean (SD) of the DSMQ scores

\begin{tabular}{|l|r|r|}
\hline & \multicolumn{1}{|c|}{ Mean } & Std. Deviation \\
\hline DSMQ sum scale & 13.2316 & 3.32740 \\
\hline Healthcare use subscale & 6.4504 & 2.35368 \\
\hline Physical activity subscale & 5.0019 & 3.18769 \\
\hline Dietary control subscale & 5.3222 & 2.45980 \\
\hline
\end{tabular}


Table 3. Multiple linear regression for the sum scale score of diabetes self-management1

\begin{tabular}{|c|c|c|c|c|}
\hline \multirow[t]{2}{*}{ Factor } & \multirow[t]{2}{*}{ Coefficient } & \multicolumn{2}{|c|}{$95 \%$ C. $I^{2}$} & \multirow[t]{2}{*}{$\mathrm{p}$ value } \\
\hline & & Lower & Upper & \\
\hline \multicolumn{5}{|l|}{ DSMQ sum scale } \\
\hline body mass index & -.094 & -.177 & -.011 & .026 \\
\hline \multicolumn{5}{|c|}{ Glucose management subscale } \\
\hline Age & 1.04 & .05 & 1.098 & .05 \\
\hline educational level & .508 & .075 & .941 & .022 \\
\hline \multicolumn{5}{|l|}{ Dietary control subscale } \\
\hline body mass index & -.070 & -.129 & -.010 & .021 \\
\hline \multicolumn{5}{|l|}{ Physical activity subscale } \\
\hline body mass index & -.091 & -.166 & -.017 & .016 \\
\hline job & -.804 & -1.573 & -.035 & .041 \\
\hline \multicolumn{5}{|l|}{ Healthcare use subscale } \\
\hline diabetes mellitus types & 1.507 & .230 & 2.784 & .021 \\
\hline diabetes treatment & .426 & .070 & .782 & .019 \\
\hline
\end{tabular}

1 The variables age, diabetes treatment, marital status, job, body mass index, gender, Diabetes duration (years), educational level, diabetes mellitus types. $95 \% \mathrm{CI}^{2}=95 \%$ confidence interval for adjusted odds ratio.

\section{Discussion}

To manage diabetes effectively and in order to control good glycaemia, patients need to have a high level of knowledge about diabetes. This can strengthen attachment to medications, an appropriate diet, and physical activity(16). Differences in findings could be due to differences in study populations as wells as the type of tools used to measures these outcomes. In this study, the overall self-care average was relatively low. Vosoghi and his colleagues had a poor level of care in research units (17). Various studies show that self-care status in diabetic patients is not in good condition, which is consistent with the result of the study and partners(18) . Baghaei et al., reported the self-care status of diabetic patients referring to the Kashan diabetes center was at moderate level(19) similar to the findings of Anbari and colleagues (20). Kassahun et al., found that a significant number of diabetic patients had a low level of knowledge, poor self-care behaviors, and a low level of medication $(21,4)$. Low education level and poor adherence to medications were poor predictors of self-concept behaviors (22). According to the findings, in the regression model, the correlation between body mass index and DSMQ sum scale was significant. In the present study, the relationship between body mass index and scores on the Dietary control subscale was significant in the regression model. This conclusion is also consistent with the various studies $(21,23-26)$. In the present study, the relationship between scores on the physical activity subscale and body mass index and job was significant. This was expected due to findings in numerous other studies. (27-31). Kriska et al show that physical activity leads to a lower incidence of type 2 diabetes in several prospective studies $(21,32-34)$. Although BMI and physical inactivity are independent predictors of diabetes, the association with BMI is more than physical activity in the combined analysis (35). Firooz et al. looked at the relationship between physical activity in patients with diabetes and self-care and claimed that there is a significant correlational between the two (36). In the study of Mashitani et al., found the quality of life associated with diabetes treatment was correlated with self-care in insulin injection, especially in Japanese patients $<65$ years with type 2 diabetes (37). Different strategies exist in different countries based on their own caring practices. Improving social protection for patients with diabetes facilitates self-care in diabetes and helps to improve glycemic control $(38,15)$. A unique challenge for optimal diabetes self-care is the integration of the various skills and behavioral changes (39). Beneficial and harmful actions of family members affects self-care and control of glycaemia in adults with type 2 diabetes (T2D) and low socioeconomic status (40). The most important person in the diabetes team is a patient who, with correct training, can play a role in controlling the disease and preventing its progress and complications(41). Evidence from earlier studies supports the concept that having good knowledge and training for good care can significantly reduce DM complications (42). If the patient's view of the disease changes as a dangerous and uncontrollable disease, it has taken an important step in controlling its illness. (43). Therefore, considering the low status of self-care behaviors in patients, community health officials must develop a comprehensive program to improve the health of these patients, paying particular attention to self-care behaviors.

Acknowledgements: The authors would like to thank the medical students of Azad University of Medical Sciences to contribution to the implementation of this study.

Conflict of interests: None declared

Funding: None

Ethical approval: Not required 


\section{References}

.1 Alrahbi H. Diabetes self-management (DSM) in Omani with type-2 diabetes. International Journal of Nursing Sciences. 2014;1(4):352-9.

.2 Zimmet P. Diabetes epidemiology as a tool to trigger diabetes research and care. Diabetologia. 1999;42(5):499-518.

.3 Sadeghi M, Ebrahimi H, Bazghaleh M. Relationship between empowerment with dimensions of quality of life and some related factors in patients with type 2 diabetes in the Shahroud city, 2013. Journal of Clinical Nursing and Midwifery. 2015;3(4):29-38.

.4 Kassahun T, Gesesew H, Mwanri L, Eshetie T. Diabetes related knowledge, self-care behaviours and adherence to medications among diabetic patients in Southwest Ethiopia: a cross-sectional survey. BMC endocrine disorders. 2016;16(1):28.

5 Markle-Reid M, Ploeg J, Fraser KD, Fisher KA, Bartholomew A, Griffith LE, et al. Community Program Improves Quality of Life and Self-Management in Older Adults with Diabetes Mellitus and Comorbidity. Journal of the American Geriatrics Society. 2017.

.6 Fauci AS. Harrison's principles of internal medicine: McGraw-Hill, Medical Publishing Division New York; 2008.

.7 Smalls BL, Gregory CM, Zoller JS, Egede LE. Effect of neighborhood factors on diabetes self-care behaviors in adults with type 2 diabetes. Diabetes research and clinical practice. 2014;106(3):435-42.

.8 Larejani B, Zahedi F. Epidemiology of diabetes mellitus in Iran. Iranian Journal of Diabetes and Lipid Disorders. 2001;1(1):1-8.

.9 Baghiani Moghadam MH, Taheri G, Fallah Zadeh H, Parsa M. The effect of instructional designed SMS based on Health Belief Model (HBM) on adoption of self-care behavior of patients with type II diabetes. Modern Care Journal (Scientific Quarterly of Birjand Nursing \& Midwifery Faculty). 2014;11(1):10-8.

.10 Shi Q, Ostwald SK, Wang S. Improving glycaemic control self-efficacy and glycaemic control behaviour in Chinese patients with Type 2 diabetes mellitus: randomised controlled trial. Journal of clinical nursing. 2010;19(3-4):398-404.

.11 Organization WH. Self-care in the context of primary health care Report of the Regional Consultation Bangkok, Thailand, 7-9 January 2009. New Delhi: World Health Organization. 2009.

.12 Weinger K, Butler HA, Welch GW, La Greca AM. Measuring diabetes self-care: a psychometric analysis of the Self-Care Inventory-Revised with adults. Diabetes care. 2005;28(6):1346-52.

.13 Butt M, Ali AM, Bakry MM, Mustafa N. Impact of a pharmacist led diabetes mellitus intervention on HbAlc, medication adherence and quality of life: A randomised controlled study. Saudi Pharmaceutical Journal. 2016;24(1):40-8.

14 Mehravar F, Mansournia MA, Holakouie-Naieni K, Nasli-Esfahani E, Mansournia N, Almasi-Hashiani A. Associations between diabetes self-management and microvascular complications in patients with type 2 diabetes. Epidemiology and health. 2016;38.

.15 Schmitt A, Gahr A, Hermanns N, Kulzer B, Huber J, Haak T. The Diabetes Self-Management Questionnaire (DSMQ): development and evaluation of an instrument to assess diabetes self-care activities associated with glycaemic control. Health and quality of life outcomes. 2013;11(1):138.

.16 Shrivastava P, Shrivastava S, Ramasamy J. An Epidemiological Study to Assess the Knowledge and Self Care Practices among Type 2 Diabetes Mellitus Patients Residing in Rural Areas of Tamil Nadu. Biol Med S. 2015;3:002.

.17 VosoghiKarkazloo N, AbootalebiDaryasari G, Farahani B, Mohammadnezhad E, Sajjadi A. The study of self-care agency in patients with diabetes (Ardabil) Modern Care Journal, affiliated to the Faculty of Nursing and Midwifery at Birjand University of Medical Sciences. 2012;4(8):197-204.

.18 shabibi p, mansourian m, abedzadeh ms, sayehmiri k. The Status of Self-Care Behaviors in Patients with Type 2 Diabetes in the City of Ilam in 2014. journal of ilam university of medical sciences. 2016;24(2):6371.

.19 Baghaei P, Zandi M, Vares Z, Masuodialavi N, Adibhajbagheri M. Diabetes mellitus patients selfcare status of Kashan diabetes center in 2005. Saze. 2008;12(1):88-93.

20 Anbari K, Gamadi K, Kaviani M, Montazeri R. Selfcare and determinants in diabetes mellitus patients of Khoramabad city. Yafteh. 2012;14(4):49-57.

.21 Tewahido D, Berhane Y. Self-Care Practices among Diabetes Patients in Addis Ababa: A Qualitative Study. PloS one. 2017;12(1):e0169062.

.22 Agrawal S. Role of self-Care in management of diabetes mellitus. The Journal of the Association of Physicians of India. 2016;64(1):92.

.23 Nti CA, Arthur D, Opare-Obisaw C. Relationship between dietary practices, physical activity and body mass indices of type 2 diabetics attending a clinic in Accra, Ghana. Journal of Public Health and Epidemiology. 2016;8(4):60-6. 
.24 Skinner TC, Hampson SE. Personal models of diabetes in relation to self-care, well-being, and glycemic control: A prospective study in adolescence. Diabetes care. 2001;24(5):828-33.

.25 Association AD. 4. Lifestyle Management: Standards of Medical Care in Diabetes-2018. Diabetes Care. 2018;41(Supplement 1):S38-S50.

.26 Tuomilehto J, Lindström J, Eriksson JG, Valle TT, Hämäläinen H, Ilanne-Parikka P, et al. Prevention of type 2 diabetes mellitus by changes in lifestyle among subjects with impaired glucose tolerance. New England Journal of Medicine. 2001;344(18):1343-50.

.27 Bouchard CE, Shephard RJ, Stephens TE, editors. Physical activity, fitness, and health: International proceedings and consensus statement. International Consensus Symposium on Physical Activity, Fitness, and Health, 2nd, May, 1992, Toronto, ON, Canada; 1994: Human Kinetics Publishers.

.28 Blair SN, Brodney S. Effects of physical inactivity and obesity on morbidity and mortality: current evidence and research issues. Medicine and science in sports and exercise. 1999;31:S646-S62.

.29 Cavanagh P, Evans WJ, Fiatarone M, Hagberg J, McAuley E, Startzell J. Position Stand Exercise and Physical Activity for Older Adults. 1998.

.30 McAuley E. Physical activity and psychosocial outcomes. 1994.

.31 Taylor RS, Brown A, Ebrahim S, Jolliffe J, Noorani H, Rees K, et al. Exercise-based rehabilitation for patients with coronary heart disease: systematic review and meta-analysis of randomized controlled trials. The American journal of medicine. 2004;116(10):682-92.

.32 Kriska AM, Saremi A, Hanson RL, Bennett PH, Kobes S, Williams DE, et al. Physical activity, obesity, and the incidence of type 2 diabetes in a high-risk population. American journal of epidemiology. 2003;158(7):669-75.

.33 Chen Q, Yi Y, Xia N, Li C, Luo Z, Huang G, et al. Prevalence of diabetes and determinants: evidence from a minority region in People's Republic of China. Therapeutics and clinical risk management. 2016;12:427.

$.34 \mathrm{Hu} \mathrm{G}$, Lindström J, Valle TT, Eriksson JG, Jousilahti P, Silventoinen K, et al. Physical activity, body mass index, and risk of type 2 diabetes in patients with normal or impaired glucose regulation. Archives of internal medicine. 2004;164(8):892-6.

.35 Weinstein AR, Sesso HD, Lee IM, Cook NR, Manson JE, Buring JE, et al. Relationship of physical activity vs body mass index with type 2 diabetes in women. Jama. 2004;292(10):1188-94.

36 Firooz M, Hosseini SJ, Mazlom SR, zadeh FH, Kimiyaee SA. Self-care of patient with diabetes type II. Journal of Sabzevar University of Medical Sciences. 2016;22(6):1018-25

.37 Mashitani T, Hayashino Y, Okamura S, Kitatani M, Furuya M, Iburi T, et al. Diabetes treatment-related quality of life is associated with levels of self-care activities in insulin injection among Japanese patients with type 2 diabetes: Diabetes Distress and Care Registry at Tenri (DDCRT 8). Acta diabetologica. 2015;52(4):639-47.

.38 Gopichandran V, Lyndon S, Angel M, Manayalil B, Blessy K, Alex R, et al. Diabetes self-care activities: a community-based survey in urban southern India. 2012.

.39 Aronson R, Brown RE, Jiandani D, Walker A, Orzech N, Mbuagbaw L. Assessment of self-management in patients with diabetes using the novel LMC Skills, Confidence and Preparedness Index (SCPI). Diabetes research and clinical practice. 2017.

.40 Mayberry LS, Berg CA, Harper KJ, Osborn CY. The design, usability, and feasibility of a family-focused diabetes self-care support mHealth intervention for diverse, low-income adults with type 2 diabetes. Journal of diabetes research. 2016;2016.

.41 aghajanian s, amozegar m. self care in diabetes mellitus patients. Electronic Journal of Shiraz University of Medical Sciences [Internet]. 201 .(6)25;4Available from: http://oldejournal.sums.ac.ir./

.42 Sinnige J, Braspenning J, Schellevis F, Stirbu-Wagner I, Westert G, Korevaar J. The prevalence of disease clusters in older adults with multiple chronic diseases-a systematic literature review .PloS one. 2013;8(11):e79641.

.43 Mahmoodi A, Alavi M, Mosavi N. the relationship between self-care behaviours and HbA1c in diabetic patients. Scientific Journal of Hamedan Nursing \& Midwifery Faculty. 2012;20(3):25-0. 